\title{
Long-term scopolamine treatment altered locomotor, exploratory and anxiety-like behaviours of albino rats
}

\author{
Asmaa K. Abdelghany ${ }^{1 *} \mathbb{D}$, Akram M. El-Kashlan² ${ }^{2}$ Hosny H. Emeash ${ }^{1}$ and Fatma Khalil ${ }^{1}$
}

\begin{abstract}
Background: Animal models are used to provide an adequate investigation of brain-behaviour, physiological and path physiological relationships to give insight into human behaviour and the underlying processes of drugs affecting the nervous system. Scopolamine; SCO (alkaloid L-(2)-scopolamine [L-(2)-hyoscine]) has a competitive inhibitory effect on muscarinic receptors for acetylcholine. Thus, this study was designated to investigate the effect of long-term SCO treatment on locomotor, exploratory and anxiety-like behaviours of rats using open field test.

Results: The long-term SCO treatment induced a prominent increase in locomotion (hyperactivity) and exploratory behaviour of rats. In addition, anxiety-like behavioural patterns showed a non-significant difference in SCO treated compared to control. Serotonin level was significantly decreased in the scopolamine treated group in comparison with the control group.
\end{abstract}

Conclusions: Data suggested that long-term SCO treatment resulted in marked neurobehavioural alterations in a rat as an animal model.

Keywords: Scopolamine, Rats, Serotonin, Exploratory behaviour, Locomotion

\section{Background}

Animal models are often included as an experimental paradigm which depends on using of the non-human species to provide an adequate investigation of brainbehaviour, physiological and path physiological relationships to give insight into human behaviour and the underlying processes $[3,40]$ of some drugs affecting the nervous system. Among these drugs, scopolamine; SCO (alkaloid L-(2)-scopolamine [L-(2)-hyoscine]) has a competitive inhibitory effect on muscarinic receptors for acetylcholine [36], acts as a non-selective muscarinic antagonist [34], affects the parasympathetic nervous system. Hence, SCO may induce signs of anxiety, avoidance,

\footnotetext{
*Correspondence: asmaa.kamal@vet.bsu.edu.eg

${ }^{1}$ Animal and Poultry Management and Wealth Development Department, Faculty of Veterinary Medicine, Beni-Suef University, Beni-Suef 62511, Egypt

Full list of author information is available at the end of the article
}

fear, and it is used to treat nausea and motion sickness in humans $[25,30,41]$. Anxiety is a status that is often accompanied by neurobehavioural signs such as depression and abnormal behaviour [37]. Scopolamine (SCO) is a muscarinic receptor antagonist (non-selective) that suppresses learning and memory through disrupting some indirect pathways and cholinergic transmission [26]. It's been commonly used as a pharmaceutical medication to simulate Alzheimer's disease-related brain damage $[5,44]$. Various tests were developed to evaluate different behavioural patterns as indicators for anxiety in rodents [32]. These tests are based on the hypothesis that, anxiety in animals is to some extent equivalent to that in human and animal models can produce a condition of anxiety that may be related to anxiety disorders $[3,9]$. Thus, an analogy can be believed, if not a homology, between humans and rodents in anxiety indicators [32]. Open field is a behavioural test based on the observation and measurement of behavioural patterns related 
to anxiety such as locomotion, exploration, and freezing in rodents [11] after their placement in the maze as a novel environment or exposure to a new stimulus [15, 32]. Furthermore, serotonin is included in the behaviour performance and mood regulation, due to its therapeutic effectiveness and extended treatment of anxiety disorders with selective serotonin reuptake inhibitors [31]. Most studies proved that short term use of SCO in treatment caused anxiety in rats and mice [10, 22], however, there is little information about the effect of long term treatment SCO on rats, behaviour and anxiety. Therefore, we aimed to investigate the effect of long term SCO treatment on locomotor, exploratory and anxiety-like behaviours of rats using open field test and measurement of brain serotonin levels.

\section{Methods}

\subsection{Chemicals}

Scopolamine (scopolamine hydrobromide, SigmaAldrich Co., USA).

\subsection{Animals}

Thirty male albino rats weighing $130-160$ g were purchased and acclimatized for two weeks before the onset of the experiment. The experimental design was approved by Institutional Animal Treatment and Use Committee.

Animals were housed in plastic cages and maintained at appropriate environmental conditions of temperature $\left(21 \pm 2{ }^{\circ} \mathrm{C}\right)$, and relative humidity $(45 \pm 5 \%)$ with a reversed 12-h light-dark cycle. Clean fresh water and feed adlibitum were available during the period of the experiment.
Thirty male albino rats were randomly selected and divided into two groups ( $n=15$ per each). Control group; injected with saline intraperitoneally (i.p); and Scopolamine hydrobromide-treated group (SCO) administered $\mathrm{SCO}$ at a dose of $2 \mathrm{mg} / \mathrm{kg}$, i.p. dissolved in saline solution $[5,10]$ daily for seven weeks.

\subsection{Open field test (OF)}

The open field test (Fig. 1) was firstly developed by Hall [19] to evaluate rodent emotional behaviour. Ohl [32] mentioned that OF test is used to assess unconditioned anxiety, where placing the animal in a novel environment is considered a stimulus that helps in the expression of anxiety symptoms as humans. The test was used to assess locomotor and exploratory behaviour in rodents qualitatively and quantitatively and anxiety behaviour $[18,42]$.

The open field maze was a wood square arena with $72 \mathrm{~cm}$ in length and $36 \mathrm{~cm}$ in height, blue lines were drawn on the floor with a marker that divide the floor into sixteen squares; each square is $18 \times 18 \mathrm{~cm}$ according to Brown et al. [8].

Nine rats were randomly selected from each group. Each rat was individually placed into one of the four corners of the open field and allowed to explore the apparatus for $5 \mathrm{~min}$. The behaviour of rats was recorded using a digital video camera. The maze floor was cleaned after each rat test using $70 \%$ ethyl alcohol.

Test parameters were analysed to assess locomotion and exploration (square crossing and rearing) and anxiety behavioural patterns according to Walsh and Cummins [43], Jahkel et al. [23], Choleris et al. [11] and Kalueff and Tuohimaa [24] as showed in Table 1.

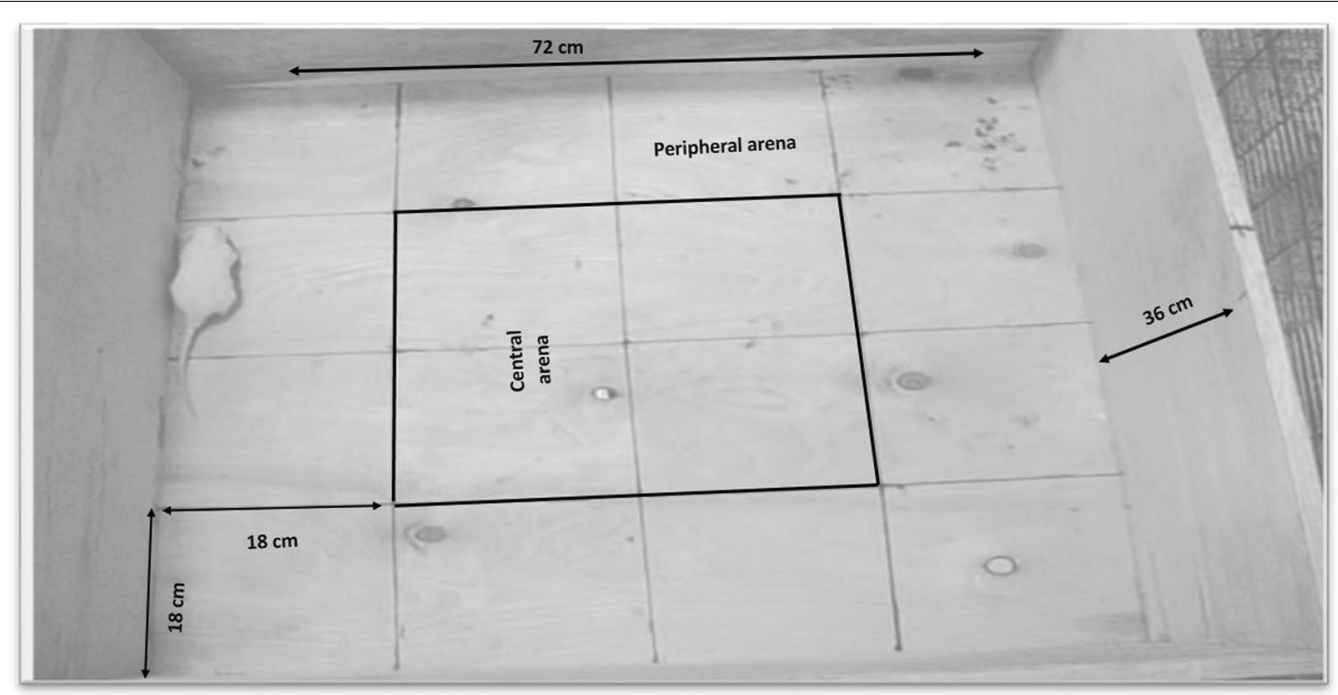

Fig. 1 Open field test apparatus (maze) 
Table 1 Open field test scoring parameters

\begin{tabular}{|c|c|}
\hline \multicolumn{2}{|l|}{ Locomotion and exploration } \\
\hline Peripheral squares crossing & Number of peripheral squares crossed with all four paws of rat \\
\hline Rearing & The frequency with which the rat stand against the wall of the maze \\
\hline Central square crossing & Frequency of central squares crossing with all four paws of rat \\
\hline Central square duration & Duration of time spent in the central squares by the rat \\
\hline \multicolumn{2}{|l|}{ Anxiety } \\
\hline Freezing & Duration of time during which the rat was completely stationary \\
\hline Stretch attend posture & $\begin{array}{l}\text { Frequency of the forward elongation of animal head and shoulders } \\
\text { followed by retraction to its original position }\end{array}$ \\
\hline Urination & The number of streaks of urine \\
\hline Defecation & Number of fecal boli produced \\
\hline
\end{tabular}

\subsection{Biochemical measurements}

After the end of behavioural tests, six rats from each group were humanely euthanized using a low dose of diethyl ether followed by rat decapitation. Then, brain samples were extracted, washed with saline and kept in a deep freezer at $-80{ }^{\circ} \mathrm{C}$. Brain homogenate was prepared for measurement of serotonin level at the National Organization for Drug Control and Research, Giza, Egypt.

\subsubsection{Estimation of the serotonin levels}

The estimation of serotonin (5-HT) levels in the rat brain was carried out according to the fluorometric method described by Ciarlone [13], where standard solution tubes and brain homogenates were centrifuged at 1000R for $5 \mathrm{~min}$. Then $2.5 \mathrm{ml}$ of supernatant fluid was transferred to tubes containing 1.6 millilitres of $0.2 \mathrm{~N}$ acetic acid and $5 \mathrm{ml}$ of heptane. All tubes were centrifuged at $1000 \mathrm{~g}$ for $5 \mathrm{~min}$ after $30 \mathrm{~min}$ on a vortex mixer. The supernatant phase of organic matter was discarded. The aqueous phase was transferred to tubes for the 5-HT analysis. All tubes were boiled for $10 \mathrm{~min}$, then cooled with tap water before being read on a spectrophotofluorometer. The excitation wavelength wavelengths were 355 and $470 \mathrm{~nm}$.

\subsection{Statistical analysis}

All data were analysed using the independent $T$-test using SPSS version 22 statistical software. The data are presented as mean \pm SE. The significance of the results was judged at a $0.05 P$ svalue. The correlation between behavioural parameters was analysed by the Pearson correlation test, followed by the principal component analysis and Varimax rotation. As well as, the correlation between behavioural parameters and biochemical data was analysed by the Pearson correlation test.

\section{Results}

Statistical analysis using the independent $T$-test revealed significant alterations in behaviours and level of brain serotonin of rats injected by SCO for seven weeks.

Regarding behaviour, Fig. 2 shows that SCO increased locomotor activity (number of peripheral square crossing and rearing) of rats (Fig. 2A). The number of peripheral squares crossed by SCO treated rats (91.25) was significantly $(P=0.01)$ more than that crossed by the control group (66.75). Additionally, SCO treated rats expressed a significant $(P=0.02)$ increase in rearing frequency (18.75) than that of the control group (9.25). Similar data were observed in exploratory behaviour, where SCO treated rats showed a significant $(P=0.01)$ increase in central square crossing (9.25) more than that crossed by those in the control group (2.00) (Fig. 2A). As well as, SCO injected rats were observed to spend a significant $(P=0.02)$ longer time in central squares $(9.75 \mathrm{~s})$ than in the control group (2.25 s) (Fig. 2B).

Moreover, anxiety-like behaviours were not significantly altered by long term SCO treatment (Fig. 3). Rats in SCO treated group spent a non-significant shorter freezing time $(0.25 \mathrm{~s})$ in the open field maze than the control group (0.75 s) (Fig. 3A). Defecation showed a nonsignificant decrease in SCO treated rats (0.00) compared to the control group (1.75). Meanwhile, SCO injected rats exhibited a non-significant increase in stretch attend posture (SAP) (2.00) with control rats (1.00) (Fig. 3B).

Furthermore, Fig. 4 declares that long-term $\mathrm{SCO}$ treatment induced a significant $(P=0.05)$ decrease $(1.00 \mu \mathrm{g} /$ gm tissue) in serotonin level in comparison to the control group $(1.72 \mu \mathrm{g} / \mathrm{gm}$ tissue).

Pearson correlation between behavioural patterns in Table 2 showed that freezing was negatively correlated with all variables at a moderate degree except with defecation (moderate positive correlation). The number of square crossing (peripheral and central), rearing and central square duration showed a good positive correlation 

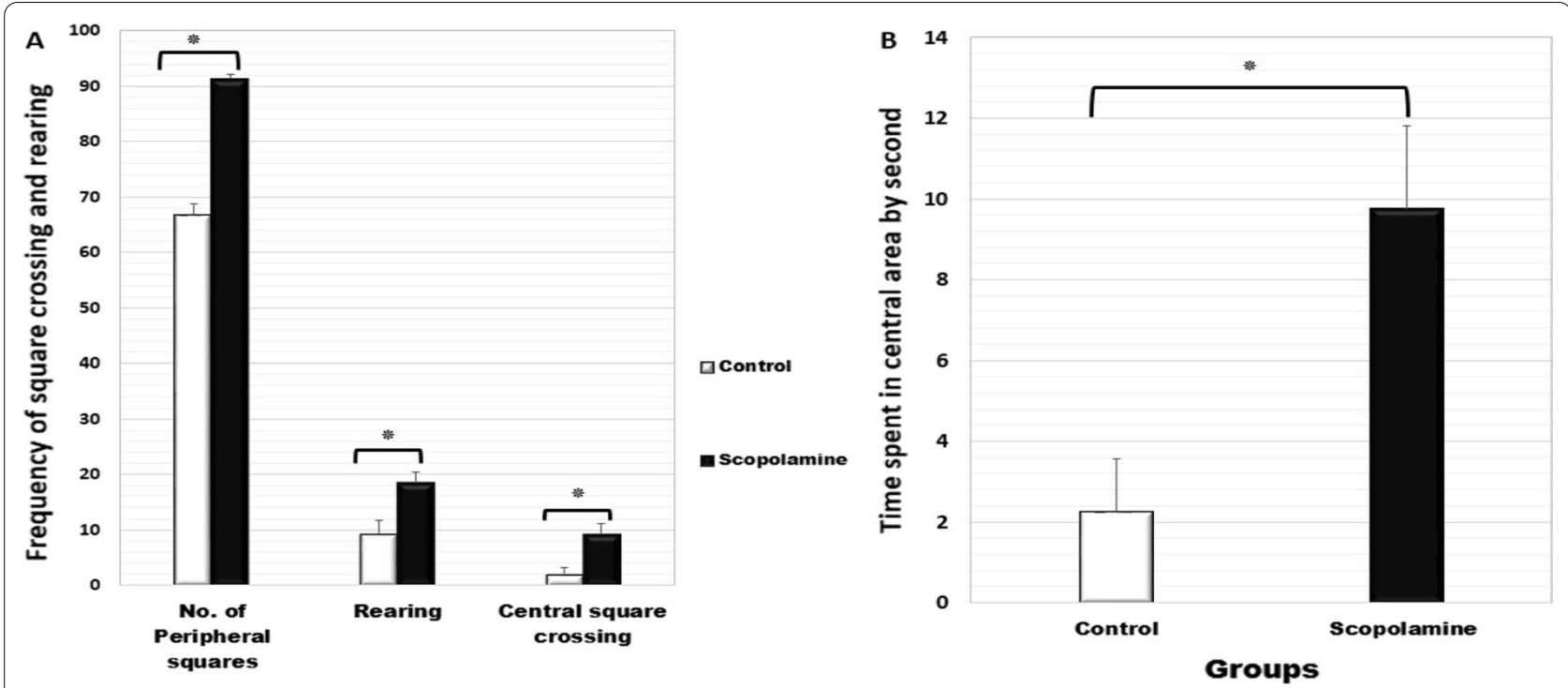

Fig. 2 Effect of long-term scopolamine treatment on locomotor activity and exploratory behaviour of rats. All values are the mean $\pm S E(n=6)$. The strike $\left(^{*}\right)$ indicates a significant difference between the control and scopolamine treated groups according to the independent $T$-test at $P<0.05$

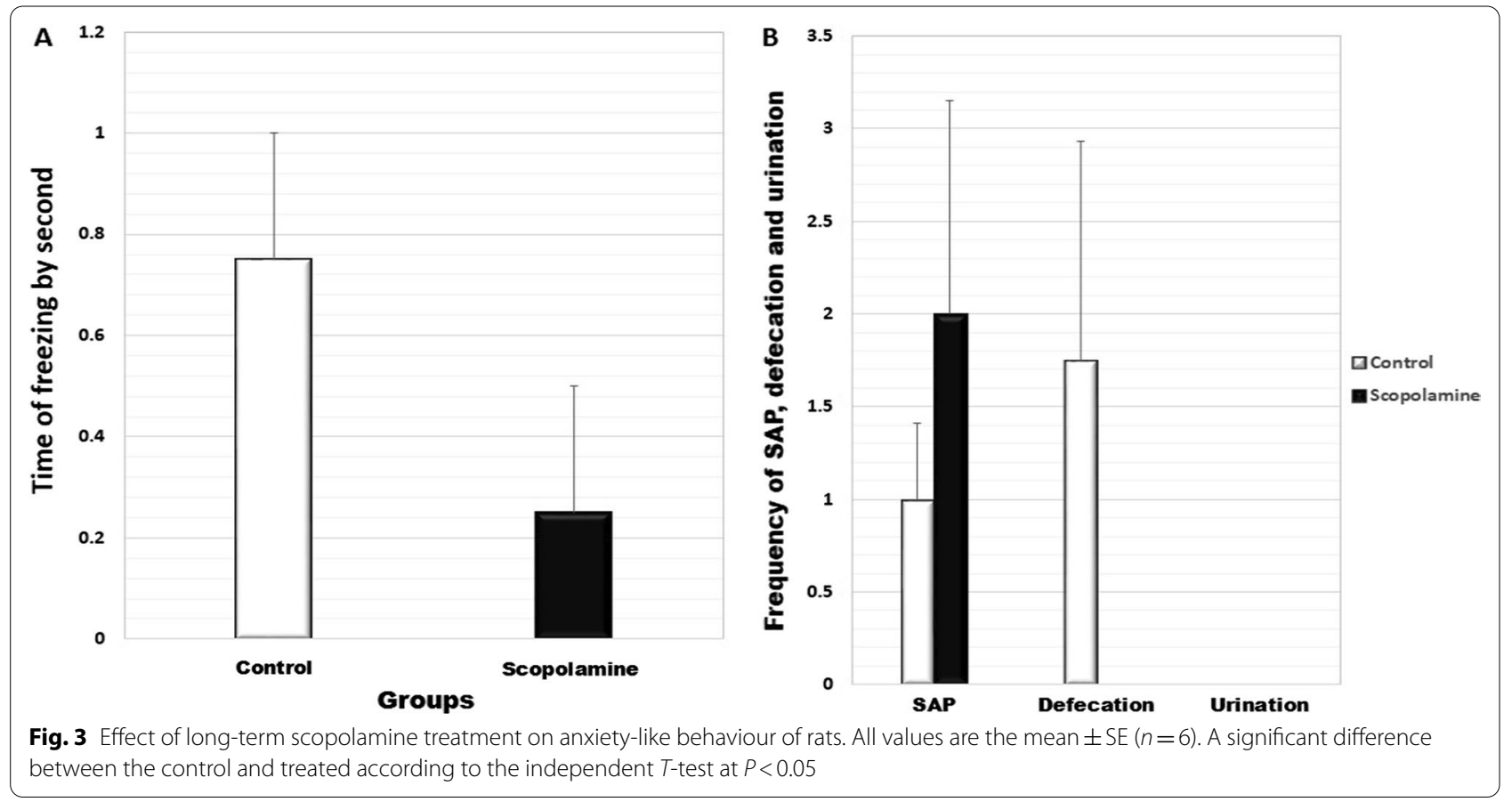

with each other. As well as, week to moderate positive correlation with SAP. On the other side, they showed a moderate negative correlation with freezing and defecation.

Factor analysis was performed using the Varimax rotation method (Table 3). It was noticed that the first component was highly correlated with No of peripheral squares (0.819), No of central squares (0.950), central square duration (0.883), rearing (0.926), and the second component was highly correlated with SAP (0.914) and Freezing $(-0.851)$. Additionally, the scree plot for factor analysis demonstrated that the data were reduced into two components as observed in Fig. 5. 


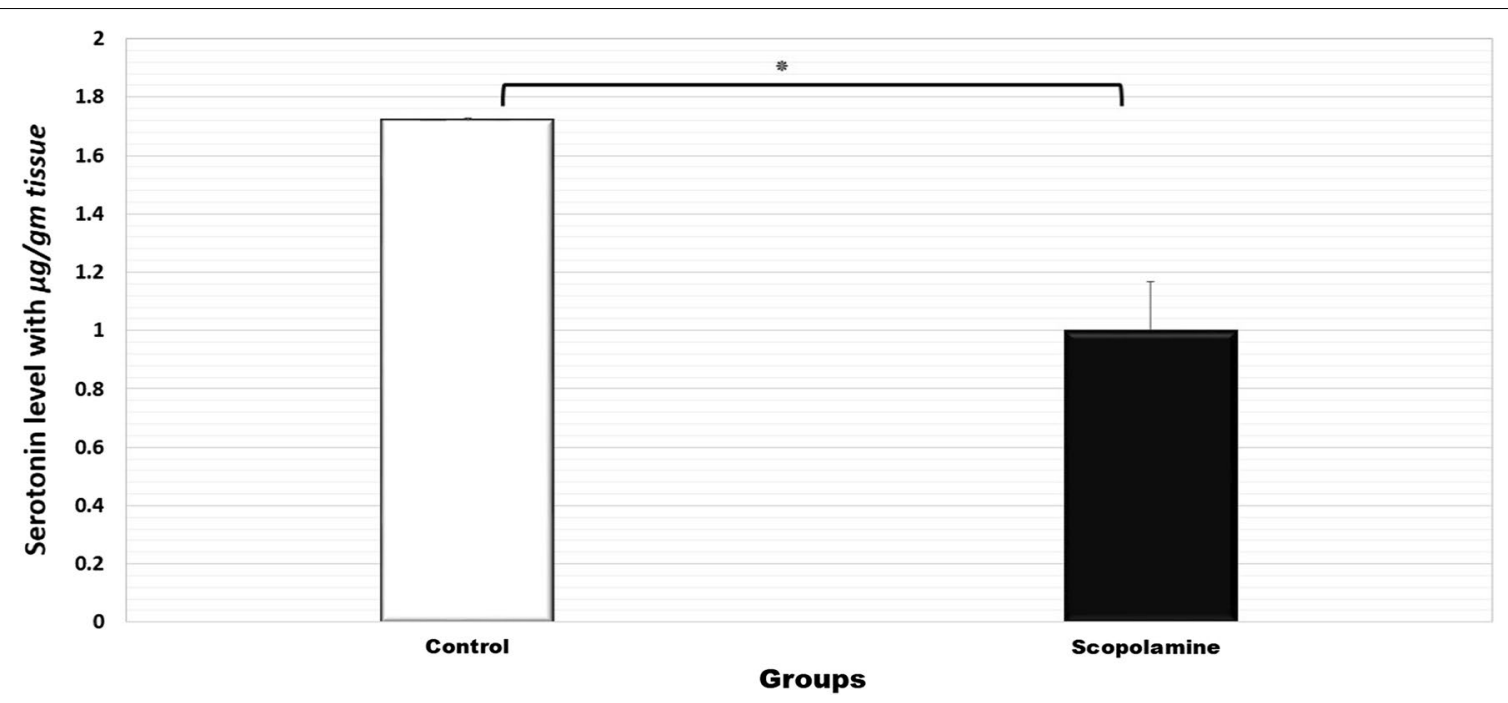

Fig. 4 Effect of long-term scopolamine treatment on brain serotonin level of rats. Data expressed as means $\pm \operatorname{SE}(n=5) .{ }^{*}$ A strike indicates a significant difference at $P \leq 0.05$

Table 2 Pearson correlation between different behavioural parameters in open field test

\begin{tabular}{|c|c|c|c|c|c|c|c|}
\hline Pearson correlation & Freezing & $\begin{array}{l}\text { No of peripheral } \\
\text { Sq crossing }\end{array}$ & $\begin{array}{l}\text { No of central Sq } \\
\text { crossing }\end{array}$ & $\begin{array}{l}\text { Central square } \\
\text { duration }\end{array}$ & Rearing & SAP & Defecation \\
\hline Freezing & 1 & -.419 & -.306 & -.417 & -.417 & -.632 & .517 \\
\hline No of peripheral Sq crossing & -.419 & 1 & .705 & $.724^{*}$ & $.718^{*}$ & .278 & -.395 \\
\hline No of central Sq crossing & -.306 & .705 & 1 & $.892^{* *}$ & $.871^{* *}$ & .237 & -.401 \\
\hline Central square duration & -.417 & $.724^{*}$ & $.892^{* *}$ & 1 & $.821^{*}$ & .478 & -.262 \\
\hline Rearing & -.417 & $.718^{*}$ & $.871^{* *}$ & $.821^{*}$ & 1 & .211 & -.259 \\
\hline Stretch attend posture (SAP) & -.632 & .278 & .237 & .478 & .211 & 1 & -.164 \\
\hline Defecation & .517 & -.395 & -.401 & -.262 & -.259 & -.164 & 1 \\
\hline
\end{tabular}

${ }^{*}$ Correlation is significant at the 0.05 level (2-tailed)

**Correlation is significant at the 0.01 level (2-tailed)

No number, Sq square

Table 3 Rotated component matrix of factor analysis (Varimax rotation)

\begin{tabular}{lcc}
\hline & \multicolumn{2}{l}{$\begin{array}{l}\text { Rotated component } \\
\text { matrix }^{\mathbf{a}}\end{array}$} \\
\cline { 2 - 3 } & \multicolumn{1}{c}{ Component } \\
\cline { 2 - 3 } & $\mathbf{1}$ & $\mathbf{2}$ \\
\hline Freezing & -.254 & -.851 \\
No of peripheral Sq crossing & .819 & .231 \\
No of central Sq crossing & .950 & \\
Central square duration & .883 & .332 \\
Rearing & .926 & .146 \\
Stretch attend posture (SAP) & .123 & .914 \\
\hline
\end{tabular}

Extraction method: principal component analysis

Rotation method: Varimax with Kaiser normalization

${ }^{a}$ Rotation converged in 3 iterations
In Table 4, Pearson correlation between behavioural patterns and serotonin level showed a good negative correlation between serotonin level and peripheral and central squares crossing, and rearing. In addition, a moderate negative correlation was found between serotonin level and central squares duration. Moreover, serotonin level showed a moderate positive correlation with defecation and freezing, while no correlation was present between serotonin level and stretch attend posture.

\section{Discussion}

Scopolamine is a potential anxiolytic drug that reduces aggressive behaviour in non-human primates under certain environmental conditions [20,33]. The open field test was a traditional test frequently used to analyse anxiety, in addition, to assessing exploratory behaviour and 


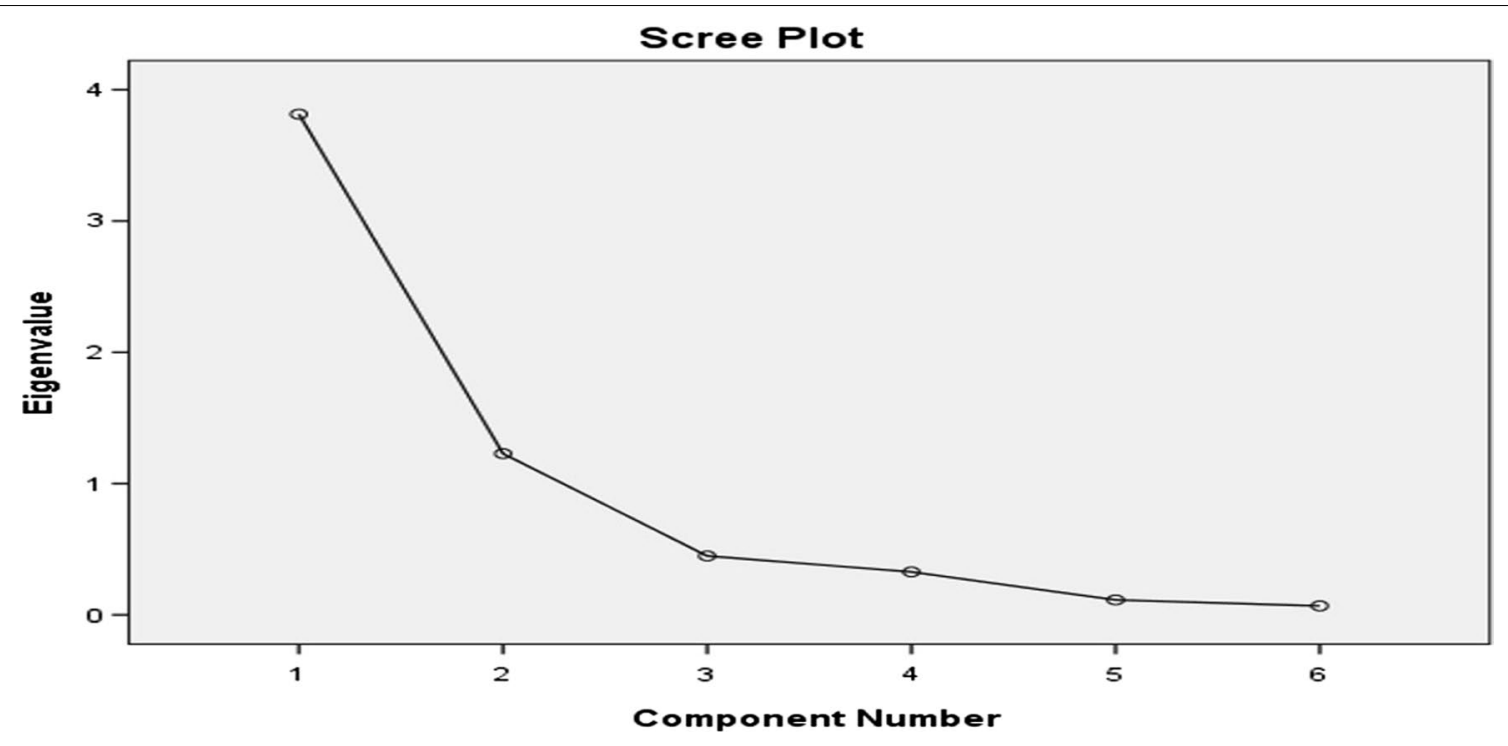

Fig. 5 Scree plot of factor analysis

Table 4 Pearson correlation between different behavioural parameters and biochemical data

\begin{tabular}{lllllllll}
\hline Pearson correlation & Freezing & $\begin{array}{l}\text { No of peripheral } \\
\text { Sq crossing }\end{array}$ & $\begin{array}{l}\text { No of central } \\
\text { Sq crossing }\end{array}$ & $\begin{array}{l}\text { Central } \\
\text { square } \\
\text { duration }\end{array}$ & Rearing & SAP & Defecation & Serotonin \\
\hline Freezing & 1 & -.419 & -.306 & -.417 & -.417 & -.632 & .517 & .370 \\
No of peripheral Sq crossing & -.419 & 1 & .705 & $.724^{*}$ & $.718^{*}$ & .278 & -.395 & $-.922^{* *}$ \\
No of central Sq crossing & -.306 & .705 & 1 & $.892^{* *}$ & $.871^{* *}$ & .237 & -.401 & $-.803^{*}$ \\
Central square duration & -.417 & $.724^{*}$ & $.892^{* *}$ & 1 & $.821^{*}$ & .478 & -.262 & -.685 \\
Rearing & -.417 & $.718^{*}$ & $.871^{* *}$ & $.821^{*}$ & 1 & .211 & -.259 & $-.813^{*}$ \\
Stretch attend posture (SAP) & -.632 & .278 & .237 & .478 & .211 & 1 & -.164 & -.021 \\
Defecation & .517 & -.395 & -.401 & -.262 & -.259 & -.164 & 1 \\
Serotonin & .370 & $-.922^{* *}$ & $-.803^{*}$ & -.685 & $-.813^{*}$ & -.021 & .502 & .502 \\
\hline
\end{tabular}

${ }^{*}$ Correlation is significant at the 0.05 level (2-tailed)

**Correlation is significant at the 0.01 level (2-tailed)

No number; $S q$ square

activity of rodents [21]. In the current study, long-term SCO administration increased activity and exploration of rats in open field maze. Likewise, Christmas and Maxwell [12] revealed that benzodiazepines (anxiolytic drugs) at low doses stimulated the animal locomotion in a novel environment. As well, Gentsch et al. [17] stated that, injecting chlordiazepoxide as an anxiolytic drug in spontaneously hypertensive rats induced an increase in both locomotion and exploratory behaviour. However, diazepam (anxiolytic drug) decreased locomotion and exploration of rats in the open field test [16].

The observed hyperactivity and increased exploration suggested that rats were less anxious in the maze. This is supported by Walsh and Cummins [43], Jafarian et al. [22] and Cheon et al. [10] who demonstrated that a high frequency of the number of peripheral square crossing and rearing in open field test indicating increased locomotor activity and/or a lower level of anxiety. In addition, Walsh and Cummins [43] and Stanford [39] reported that rats spent most of their time in the central area and explore more in open field test reflect a low level of anxiety. On the other hand, Archer [1] found that hyperactivity in a novel maze may indicate a high-stress state of animals. The observed increase in activity was correlated with the recorded non-significant decrease in freezing, where rats spent more time performing rearing and exploration and thus little time remained for freezing. The reduction in freezing time and defecation frequency confirmed our 
suggestion that long-term SCO treatment decreased anxiety in rats $[11,38]$. Furthermore, the recorded non-significant increase in stretch attend posture meant that rats had the motivation to explore open field maze and thus, became less afraid in the maze [11]. On the contrary, Bindra and Thmpson [6] proposed frequent defecation of rats in a novel environment as a sign of emotionality and it is not an index of anxiety. Unlike our hypothesis, stretch attend posture is considered anxiety-like behaviour and indicated that the animal was hesitant to move due to a high level of anxiety [7]. Serotonin has a marked role in animal anxiety $[27,28]$. Thus, the observed anxiolytic behaviour caused by long-term SCO treatment may be explained by the reported decrease of serotonin in the current study. This is proved by Bert et al. [2] demonstrated that serotonin (5-HT) increased with anxiety and decreased with anxiolytic drugs in different rat stocks and strains. Moreover, anxiety was increased following a potentiated 5-HT release during the stay on the X-maze [4]. Furthermore, central administration of 5-HT led to an anxiogenic-like behaviour [45]. Additionally, Cook and Sepinwall [14] found that non-selective 5-HT antagonists application induced an anxiolytic-like behaviour. On the other side, Murphy et al. [29] demonstrated that reduced serotonin tissue levels as a result of serotonin transporter deletion increased anxiety-like behaviours which is clearer in female mice than males. The obtained decrease in brain serotonin level caused by SCO treatment is agreeable with Ramakrishnan et al. [35] who reported that intraperitoneal injection of SCO to mice caused a significant decrease in serotonin level in comparison with the control group. Our data were disagreeable with Zaki et al. [46] who observed that administration of SCO at a dose of $20 \mathrm{mg} \backslash \mathrm{kg}$ via intraperitoneal injection for seven days increased serotonin level in SCO treated rats compared to control rats. This difference in data is attributed to different doses, duration and tested animal strain, age and sex [2]. Further studies are highly required to evaluate the effect of different doses of $\mathrm{SCO}$ on the anxiolytic behaviour of rats as an animal model at different durations and doses and in various behavioural tests.

\section{Conclusions}

Our study suggested that long-term SCO treatment induced neurobehavioural alterations included an increase in locomotor and exploratory behaviours and a decrease in anxiety which was accompanied by low brain serotonin levels in rats as an animal model. However, further studies are required to investigate the effect of longterm SCO treatment on anxiety-related behaviour of rats using other anxiety assessment behavioural tests.

\section{Acknowledgements}

Not applicable.

\section{Authors' contributions}

All authors (AKA, AEL, HE, FK) equally contributed to this study. The conception OR design of the work: HE and AKA shared the work conception and design. Analysis: AKA performed the analysis of behaviour, AEL carried out the biochemical analysis, and AKA and FK performed the work statistical analysis. Interpretation, work drafting and revision of data: FK and AKA shared data writing and revision. Manuscript reviewing: HE reviewed the manuscript. All authors have read and approved the final manuscript.

\section{Funding}

Not applicable.

\section{Availability of data and materials}

The datasets generated and/or analysed during the current study are not publicly available but are available from the corresponding author if needed.

\section{Declarations}

\section{Ethics approval and consent to participate}

The experimental design was approved by Beni-Suef University Institutional Animal Treatment and Use Committee (BSU-IACUC), approval number (018.50). http://www.bsu.edu.eg/Content.aspx?section_id=3291\&cat_id=43\& lang=enln.

\section{Consent for publication}

Not applicable.

\section{Competing interests}

The authors declare that they have no competing interests.

\section{Author details}

${ }^{1}$ Animal and Poultry Management and Wealth Development Department, Faculty of Veterinary Medicine, Beni-Suef University, Beni-Suef 62511, Egypt. ${ }^{2}$ Biochemistry Department, Faculty of Pharmacy, University of Sadat City, Monufia, Egypt.

Received: 13 April 2021 Accepted: 20 December 2021

Published online: 10 January 2022

References

1. Archer J (1973) Tests for emotionality in rats and mice: a review. Anim Behav 21(2):205-235. https://doi.org/10.1016/S0003-3472(73)80065-X

2. Bert B, Fink H, Sohr R, Rex A (2001) Different effects of diazepam in Fischer rats and two stocks of Wistar rats in tests of anxiety. Pharmacol Biochem Behav 70(2-3):411-420. https://doi.org/10.1016/s0091-3057(01)00629-3

3. Bertoglio L J, de Pádua Carobrez A (2016) Animal tests for anxiety. In: Andersen M, Tufik S (eds) Rodent model as tools in ethical biomedical research. Springer, Cham. https://doi.org/10.1007/978-3-319-11578-8_18

4. Bickerdike MJ, Fletcher A, Marsden CA (1995) Attenuation of CCK-induced aversion in rats on the elevated $\mathrm{x}$-maze by the selective 5-HT1A receptor antagonists (+) WAY100135 and WAY100635. Neuropharmacology 34(7):805-811. https://doi.org/10.1016/0028-3908(95)00037-7

5. Bihaqi SW, Singh AP, Tiwari M (2012) Supplementation of convolvulus pluricaulis attenuates scopolamine-induced increased Tau and amyloid precursor protein (AbetaPP) expression in rat brain. Indian J Pharmacol 44(5):593-598. https://doi.org/10.4103/0253-7613.100383

6. Bindra D, Thompson WR (1953) An evaluation of defecation and urination as measures of fearfulness. J Comp Physiol Psychol 46(1):43. https://doi. org/10.1037/h0057952

7. Blanchard DC, Griebel G, Blanchard RJ (2001) Mouse defensive behaviors: pharmacological and behavioral assays for anxiety and panic. Neurosci Biobehav Rev 25(3):205-218. https://doi.org/10.1016/S0149-7634(01) 00009-4 
8. Brown RE, Corey SC, Moore AK (1999) Differences in measures of exploration and fear in MHC-congenic C57BL/6J and B6-H-2K mice. Behav Genet 29:263-271. https://doi.org/10.1023/A:1021694307672

9. Campos CA, Fogaça MV, Aguiar DC, Guimarães FS (2013) Animal models of anxiety disorders and stress. Rev Bras Psiquiatr 35:S101-S111. https:// doi.org/10.1590/1516-4446-2013-1139

10. Cheon SY, Koo B, Kim SY et al (2020) Scopolamine-induced delirium promotes neuroinflammation and neuropsychiatric disorder in mice. Res Square 6:66

11. Choleris E, Thomas AW, Kavaliers M, Prato FS (2001) A detailed ethological analysis of the mouse open field test: effects of diazepam, chlordiazepoxide and an extremely low frequency pulsed magnetic field. Neurosci Biobehav Rev 25(3):235-260. https://doi.org/10.1016/S0149-7634(01) 00011-2

12. Christmas AJ, Maxwell DR (1970) A comparison of the effects of some benzodiazepines and other drugs on aggressive and exploratory behaviour in mice and rats. Neuropharmacology 9(1):17-29. https://doi.org/10. 1016/0028-3908(70)90044-4

13. Ciarlone AE (1978) Further modification of a fluorometric method for analyzing brain amines. Microchem J 23:9-12. https://doi.org/10.1016/ 0026-265X(78)90034-6

14. Cook L, Sepinwall J (1975) Behavioral analysis of the effects and mechanisms of action of benzodiazepines. Adv Biochem Psychopharmacol $14: 1-28$

15. Ennaceur A (2014) Tests of unconditioned anxiety — pitfalls and disappointments. Physiol Behav 135:55-71. https://doi.org/10.1016/j.physbeh. 2014.05.032

16. Fisher CE, Hughes RN (1996) Effects of diazepam and cyclohexyladenosine on open-field behavior in rats perinatally exposed to caffeine. Life Sc 58(8):701-709. https://doi.org/10.1016/S0024-3205(96)80009-9

17. Gentsch C, Lichtsteiner M, Feer H (1987) Open field and elevated plusmaze: a behavioural comparison between spontaneously hypertensive (SHR) and Wistar-Kyoto (WKY) rats and the effects of chlordiazepoxide. Behav Brain Res 25(2):101-107. https://doi.org/10.1016/0166-4328(87) 90003-9

18. Gould TD, Dao DT, Kovacsics CE (2009) The open field test. In: Mood and anxiety related phenotypes in mice: Characterization using behavioural tests. Springer, pp 1-2042. https://doi.org/10.1007/978-1-60761-303-9

19. Hall CS (1934) Emotional behavior in the rat. I. Defecation and urination as measures of individual differences in emotionality. J Comp Psychol 18(3):385

20. Hamilton TJ, Morrill A, Lucas K et al (2017) Establishing zebrafish as a model to study the anxiolytic effects of scopolamine. Sci Rep 7:15081. https://doi.org/10.1038/s41598-017-15374-w

21. Hines TJ, Minton BR (2012) Effects of environmental enrichment on rat behavior in the open field test. NCURi, https://www.researchgate.net/ profile/Tim-Hines/publication/306057513

22. Jafarian S, Ling K, Hassan Z et al (2019) Effect of zerumbone on scopolamine-induced memory impairment and anxiety-like behaviours in rats, Alzheimer's \& Dementia. Transl Res Clin Interven 5:637-643. https://doi. org/10.1016/.t.trci.2019.09.009

23. Jahkel M, Rilke O, Koch R, Oehler J (2000) Open field locomotion and neurotransmission in mice evaluated by principal component factor analysis-effects of housing condition, individual activity disposition and psychotropic drugs. Prog Neuro-Psychopharmacol Boil Psychiatry 24:61-84. https://doi.org/10.1016/s0278-5846(99)00081-0

24. Kalueff AV, Tuohimaa P (2004) Experimental modeling of anxiety and depression. Acta Neurobiol Exp 64(4):439-448

25. Klinkenberg I, Blokland A (2010) The validity of scopolamine as a pharmacological model for cognitive impairment: a review of animal behavioral studies. Neurosci Biobehav Rev 34:1307-1350. https://doi.org/10.1016/j. neubiorev.2010.04.001

26. Liu T, Xia Z, Zhang WW, Xu JR, Ge XX, Li J, Cui Y, Qiu ZB, Xu J, Xie Q, Wang H (2013) Bis (9)-(-)-nor-meptazinol as a novel dual-binding AChEl potently ameliorates scopolamine-induced cognitive deficits in mice. Pharmacol Biochem Behav 104:138-143. https://doi.org/10.1016/j.pbb. 2012.11.009

27. Mällo T, Kõiv K, Koppel I et al (2008) Regulation of extracellular serotonin levels and brain-derived neurotrophic factor in rats with high and low exploratory activity. Brain Res 1194(5):110-117. https://doi.org/10.1016/j. brainres.2007.11.041
28. Morilak DA, Frazer A (2004) Antidepressants and brain monoaminergic systems: a dimensional approach to understanding their behavioural effects in depression and anxiety disorders. Int J Neuropsychopharmacol 7(2):193-218. https://doi.org/10.1017/S1461145704004080

29. Murphy DL, Li Q, Engel S, Wichems C, Andrews A, Lesch KP, Uhl G (2001) Genetic perspectives on the serotonin transporter. Brain Res Bull 56(5):487-494. https://doi.org/10.1016/S0361-9230(01)00622-0

30. Nachum Z, Shupak A, Gordon CR (2006) Transdermal scopolamine for prevention of motion sickness. Clin Pharmacokinet Therap Appl 45:543-566. https://doi.org/10.2165/00003088-200645060-00001

31. Nazar M, Siemiatkowski M, Bidziński A, Członkowska A et al (1999) The influence of serotonin depletion on rat behavior in the Vogel test and brain 3H-zolpidem binding. J Neural Transm 106(5-6):355-68. https://doi. org/10.1007/s007020050164

32. Ohl F (2003) Testing for anxiety. Clin Neurosci Res 3(4-5):233-238. https:// doi.org/10.1016/S1566-2772(03)00084-7

33. Plotnik R, Mollenauer S, Gore W, Popov A (1975) Comparing the effects of scopolamine on operant and aggressive responses in squirrel monkeys. Pharmacol Biochem Behav 3(5):739-748. https://doi.org/10.1016/00913057(75)90100-8

34. Popović M, Giménez de Béjar V, Popović N, Caballero-Bleda M (2015) Time course of scopolamine effect on memory consolidation and forgetting in rats. Neurobiol Learn Mem 118:49-54. https://doi.org/10.1016/j.nIm.2014. 11.006

35. Ramakrishnan $P$, Chandrasekhar T, Muralidharan P (2015) Cognitive enhancing, anti-acetylcholinesterase, and antioxidant properties of Tagetes patula on scopolamine-induced amnesia in mice. Int J Green Pharm 9:167-174. https://doi.org/10.4103/0973-8258.161234b

36. Renner UD, Oertel R, Kirch W (2005) Pharmacokinetics and pharmacodynamics in clinical use of scopolamine. Ther Drug Monit 27(5):655-665. https://doi.org/10.1097/01.ftd.0000168293.48226.57

37. Salloway S, Harrington C, Jacobson S (2006) Psychiatric evaluation of the neurological patient. In: Jests DV, Friedman JH. (eds) Psychiatry for neurologists. Current clinical neurology. Humana Press. https://doi.org/ 10.1007/978-1-59259-960-8_3

38. Sethi P, Jyoti A, Singh R, Hussain E, Sharma D (2008) Aluminium-induced electrophysiological, biochemical and cognitive modifications in the hippocampus of aging rats. Neurotoxicology 29(6):1069-1079. https://doi. org/10.1016/j.neuro.2008.08.005

39. Stanford SC (2007) The open field test: reinventing the wheel. J Psychopharmacol 21(2):134-136. https://doi.org/10.1177/0269881107073199

40. Steimer $T$ (2011) Animal models of anxiety disorders in rats and mice: some conceptual issues. Dialog Clin Neurosci 13(4):495-506. https://doi. org/10.31887/DCNS.2011.13.4/tsteimer

41. Thomas T, Dooley T (2018) Treatment of anxiety prior to a medical procedure using an atenolol_-scopolamine combination drug. J Depress Anxiety 7:1-5. https://doi.org/10.4172/2167-1044.1000303

42. Valvassori SS, Varela RB, Quevedo J (2017) Animal models of mood disorders: focus on bipolar disorder and depression. In: Animal models for the study of human disease, pp 991-1001. Academic press', https://doi.org/ 10.1016/B978-0-12-809468-6.00038-3

43. Walsh RN, Cummins RA (1976) The open-field test: a critical review. Psychol Bull 83:482-504. https://doi.org/10.1037/0033-2909.83.3.482

44. Wang $X$, Wang ZH, Wu YY, Tang H, Tan L, Wang X, Gao XY, Xiong YS, Liu D, Wang JZ, Zhu LQ (2013) Melatonin attenuates scopolamine-induced memory/synaptic disorder by rescuing EPACs/miR-124/Egr1 pathway. Mol Neurobiol 47(1):373-381. https://doi.org/10.1007/s12035-012-8355-9

45. Wise CD, Berger BD, Stein L (1972) Benzodiazepines: anxiety-reducing activity by reduction of serotonin turnover in the brain. Science 177(4044):180-183. https://doi.org/10.1126/science.177.4044.180

46. Zaki HF, Abd-El-Fattah MA, Amina S, Attia AS (2014) Naringenin protects against scopolamine-induced dementia in rats. Bull Facul Pharms 52(1):15-25. https://doi.org/10.1016/j.bfopcu.2013.11.001

\section{Publisher's Note}

Springer Nature remains neutral with regard to jurisdictional claims in published maps and institutional affiliations. 